\title{
Revisiting Authenticity in the Age of the Digital Transformation of Cultural Tourism
}

\author{
Maria Shehade and Theopisti Stylianou-Lambert
}

\begin{abstract}
The recent years have seen a digital transformation of the cultural tourism sector and the interpretation of cultural heritage, through the use of emerging and immersive technologies, such as Virtual Reality (VR) and Augmented Reality (AR). Although this transformation has brought important advantages, it may also challenge the authenticity of the offered experience. This paper aims to explore the different and conflicting scholarly debates on authenticity and technology, which lie at the intersection of three fields, namely tourism studies, heritage studies and ICT and which may also have consequences on the actual applicability of such technologies in cultural tourism. An examination of the concept of authenticity in the aforementioned disciplines is provided, through an analysis of how the concept has evolved in each of the three disciplines. The paper also highlights their differences and points of convergence and discusses the challenges and implications created by the identified discrepancies between the different stakeholders involved in cultural tourism. Finally, suggestions will be offered on how the discussed challenges and implications can be addressed in light of the new needs of cultural tourism in the digital era.
\end{abstract}

JEL Classification $\mathrm{Z} 10 \cdot \mathrm{Z} 30$

\footnotetext{
M. Shehade $(\bowtie)$

Research Centre on Interactive Media, Smart Systems and Emerging Technologies (RISE), Nicosia, Cyprus

e-mail: maria.shehade.09@ucl.ac.uk

T. Stylianou-Lambert

Research Centre on Interactive Media, Smart Systems and Emerging Technologies (RISE), Nicosia, Cyprus

Cyprus University of Technology, Limassol, Cyprus
}

V. Katsoni, T. Spyriadis (eds.), Cultural and Tourism Innovation in the Digital Era, Springer Proceedings in Business and Economics, https://doi.org/10.1007/978-3-030-36342-0_1 


\section{Introduction}

The recent years have seen a tremendous development in information and communication technologies (ICTs), transforming the cultural tourism sector and the interpretation of cultural heritage. The rapid advancement of emerging and immersive technologies, such as Virtual Reality (VR) and Augmented Reality (AR), and their adoption by cultural sites and museums has brought important advantages but also certain challenges that need to be discussed. As will be argued in this paper, as emerging technologies continue to be integrated into cultural tourism experiences, it is imperative to revisit particular challenging aspects of their application.

One of the biggest challenges faced by VR/AR applications is the authenticity of the offered experience. As will be illustrated further below, current debates on authenticity and technology lie at the intersection of three fields, namely tourism studies, heritage studies and ICT, creating different and sometimes conflicting perspectives but also conflicts between professionals from these fields, with consequences on the actual applicability of such technologies in cultural tourism. Thus, the concept of authenticity proved to be a dynamic, controversial and extremely fluid concept, igniting 'many debates regarding its meaning and utility, resulting in several theoretical perspectives' (Rickly-Boyd 2011, 1).

This paper aims to explore the different and conflicting scholarly debates and approaches on authenticity and revisit the notion of authenticity in light of the new developments on emerging and immersive technologies. This will be mainly conducted from the perspective of current research in the fields of cultural tourism and heritage management. The paper will attempt to provide an answer to what authenticity may entail in the digital era and at the intersections of the involved disciplines and which implications and challenges these definitions entail.

The paper starts with an examination of the concept of authenticity, providing an overview of how authenticity is perceived in cultural tourism studies, heritage management studies and the ICT field and how the concept has evolved in each of the three disciplines. The next section brings together all approaches discussed, highlighting their differences as well as points of convergence and discusses the challenges and implications created by the identified discrepancies between the different stakeholders involved in cultural tourism. The final section of the paper discusses a possible way forward offering suggestions on how the discussed challenges and implications can be addressed in light of the new needs of cultural tourism in the digital era. 


\section{Authenticity at the Intersection of Tourism Studies, Cultural Heritage and ICT}

\subsection{Tourism Studies}

As noted by Belhassen et al. (2008, 668), 'the search for authenticity has become one of the key themes in the academic literature on tourism'. The term has 'undergone a series of conceptual shifts' (ibid) which were mapped by Wang (1999) into a classification of the different approaches towards authenticity in tourism studies. Wang identified three approaches towards authenticity, namely objectivist, constructivist and postmodernist, which are reflected in three different types of authenticity: objective, constructive and existential (see also Dueholm and Smed 2014; Belhassen et al. 2008).

According to the objective approach, authenticity is linked to the originality of the 'toured object', which is judged based on measurable and objective criteria set by 'experts' (Wang 1999). Thus, replicas could never be seen as authentic, even if 'the tourists themselves think they have gained authentic experiences' (ibid, 351). This is also linked to the notion of 'staged authenticity', introduced by MacCannell, who noted that authenticity can be staged as something false, 'totally set up in advance for touristic visitation' $(1973,597)$. According to this approach, if tourists seek the original they may fall victims of this staged authenticity (see also Wang 1999, 353; Chhabra et al. 2003). Thus, such experiences cannot be counted as authentic even if they are perceived as such by the visitor.

If this approach is linked to the use of VR/AR, then the experience becomes inauthentic since the 'toured object' is replaced by a digital reconstruction and thus we can consider VR/AR environments 'inherently inauthentic' (Guttentag 2010; Dueholm and Smed 2014).

According to the constructivist approach, authenticity should be seen not as an inherent property of the object but rather as a pluralistic social process, 'constructed and negotiated by its subjective audiences' (Dueholm and Smed 2014, 289). According to this approach, authenticity is constructed based on the tourists' own 'beliefs, expectations, preferences, stereotypical images and consciousness onto the toured objects', which is why it should be viewed as relative and 'dependent on the single individual's subjective perception and interpretation of authenticity' (ibid). This also relates to what Cohen and Cohen (2012) have called 'hot authentication', a process which involves individual emotion and beliefs that are subjective and cannot be judged and which are formed by an immersion of the visitor in the individually constructed experience.

The postmodernist approach does not consider inauthenticity as a problem and stresses the notion of 'hyperreality', thus deconstructing authenticity concepts (Wang 1999). As Rickly-Boyd explains, the hyperreal is a 'simulated experience that fulfils the desire for the real' $(2011,273)$. According to postmodernists, the boundaries are blurred between the copy and the original and therefore, authenticity depends on the quality of the representation and on how convincing it is (McCrone et al., quoted in Wang 1999, 357). In this context, it has been suggested that 
inauthenticity should be accepted in tourism experiences, since tourists are in 'search for enjoyment' and are less concerned with the authenticity of original objects (Cohen 1995). Thus, tourists are willing to accept historical inaccuracies and 'staged authenticity' as a substitute for the protection of the original (ibid). This is especially so in cases where this staged authenticity protects 'a fragile toured culture and community from being disturbed' (Wang 1999, 357) or when the original is very sensitive and mass tourism may cause its degradation.

As Wang suggests, this deconstruction of authenticity, 'paves the way to define existential authenticity as an alternative experience in tourism' $(1999,358)$. In this frame of thought, authenticity should be seen as an emotional and creative experience, which is defined by the tourist instead of the toured object. Thus, 'authenticity is an existential state in which one is true to one's real self in a given moment' (Belhassen et al. 2008, 671) and in which personal feelings are generated by activities in which the cultural tourist is involved.

Modern technology, and especially VR/AR, may prove an excellent facilitator of this approach, since it can make the inauthentic look very close to the original. Nevertheless, this approach may result in several implications, discussed later on in the third section of the paper.

\subsection{Cultural Heritage Studies}

The concept of authenticity proved a highly controversial issue in the field of cultural heritage and heritage management. As Aplin argues $(2002,130)$ 'the questions of originality and authenticity are vexed, frequently difficult to resolve, and perhaps the most divisive issues faced by the heritage community'.

There are many different notions associated with authenticity and the complexity of the term is evident in how it evolved and expanded through time. As Lowenthal stresses, 'authenticity is in continual flux, its defining criteria subject to ceaseless change. The standards by which we gauge it change over time, with circumstance, place and culture' $(1999,1)$. The issue of authenticity started to attract attention in the nineteenth century especially because of the debates on the preservation of historic buildings and their contribution to the construction of national identity and memory (Silverman 2015; Lowenthal 1990). The first debates on authenticity were initiated by John Ruskin, who opposed the restoration of the physical fabric of historic buildings, noting that authenticity was evidenced by all changes in fabric and so the degradation of the fabric is part of what makes historic buildings authentic (1849).

The debates and controversy surrounding authenticity, especially in relation to how cultural heritage is preserved, are evident in a series of conventions and charters. Authenticity first appears as a term in the 1964 Venice Charter ${ }^{1}$

\footnotetext{
${ }^{1}$ For the full text of the Charter see https://www.icomos.org/charters/venice_e.pdf (Accessed 3 June 2019).
} 
(International Charter for the Conservation and Restoration of Monuments), although the 1931 Athens Charter for the Restoration of Historic Monuments also tried to argue for the protection of the 'ancient character' of monuments. In the context of the Venice Charter, authenticity is associated with the original fabric, i.e. the originality of material, and the idea of minimum intervention is spread across the whole text. The charter focuses on the authenticity of materials without mentioning anything about other forms of authenticity which were highlighted by following charters.

The Venice Charter deeply affected the 1972 UNESCO World Heritage Convention. ${ }^{2}$ The earliest versions of the 'Operational guidelines for the implementation of the world heritage convention', stressed the need for each heritage site nominated for the world heritage list to 'meet the test of authenticity in design, material, workmanship or setting'. However, since 2005, the newest versions of the Operational Guidelines were revised to become aligned with new notions of authenticity, introduced by the 1994 Nara Document on Authenticity. ${ }^{3}$ The Nara Document resulted from the many problems created by the definitions of authenticity set in the Venice Charter and the Operational Guidelines, which did not take into consideration the different meanings that authenticity could entail in different cultural contexts as well as the non-material expressions of authenticity linked with intangible heritage.

The most important element of the document is the conclusion that it is not possible to base judgments of value and authenticity on fixed criteria. Instead, cultural heritage must be considered and judged within the cultural contexts to which it belongs' (Article 11). Furthermore, authenticity judgments may be linked to various aspects such as 'form and design, materials and substance, use and function, traditions and techniques, location and setting, spirit and feeling' (Article 13). Effectively authenticity was no longer something static or straightforward, but something more complex and diverse than originally thought, largely dependent upon the values associated with each site.

This was further recognized by the 1996 Declaration of San Antonio, ${ }^{4}$ which connected authenticity with identity, stating that 'the authenticity of our cultural heritage is directly related to our cultural identity' (Article 1). It also acknowledged that 'authenticity is a concept much larger than material integrity' (Article 3) and it can reside in the values attached to heritage by the communities that have a stake in it (Article 7). Quite interestingly, the declaration clearly acknowledges tourists as a stakeholder group (see Silverman 2015).

\footnotetext{
${ }^{2}$ For the full text of the Convention see https://whc.unesco.org/archive/convention-en.pdf (Accessed 3 June 2019).

${ }^{3}$ For the full text of the Document see https://www.icomos.org/charters/nara-e.pdf (Accessed 3 June 2019).

${ }^{4}$ For the full text of the Declaration see https://www.icomos.org/en/charters-and-texts/179-articlesen-francais/ressources/charters-and-standards/188-the-declaration-of-san-antonio (Accessed 3 June 2019).
} 
Despite the aforementioned institutionalization of the concept of authenticity from international organizations such as UNESCO and ICOMOS and its evolution to incorporate different or conflicting views of authenticity, many scholars have acknowledged that the concept has been largely affected by what Smith defines as Authorized Heritage Discourse (AHD; Smith 2006). In the context of AHD, heritage is 'constructed' and 'controlled' by the authoritative voice of heritage specialists, due to their 'ability to claim expert authority over material culture' (Smith 2006, 26). In essence, as Smith notes, 'the power relations underlying the discourse identify those people who have the ability or authority to 'speak' about or 'for' heritage ... and those who do not' $(2006,12)$ and thus, the meaning of authenticity is still largely defined by the AHD, resulting in several implications, discussed in Sect. 3.

Nevertheless, the concept of authenticity is still evolving, especially in light of the developments in the fields of both new technologies and cultural tourism. Thus, new approaches to authenticity are discussed, in an attempt to address the implications arising from more 'rigid' definitions of authenticity, with scholars proposing new approaches such as 'contemporary authenticity'. As Silverman explains, contemporary authenticity is linked to 'the dynamism of social life' $(2015,85)$. This approach recognizes that:

forces such as globalization, commercialization, mass communication and tourism are generating new cultural manifestations in tangible and intangible form, which may be brand new or revisions but are embedded in active situations. Contemporary authenticity works from the premise that society generates new contexts in which human beings produce meaningful acts and objects without necessarily bringing the past 'faithfully' into the present (Silverman 2015, 85).

As we can see, in the field of heritage studies, the concept of authenticity has evolved from an emphasis on objects, materials and immediate context, into a more relational and socially constructed notion. Issues of authority and who has the privilege to define something as authentic are still considered important issues. Having said that, the focal point of authenticity still remains on the object itself, the experts that define it as authentic and the object's relationship with people.

\section{$2.3 \quad$ ICT}

The rapid advancements of VR/AR technology have greatly affected the tourism industry, with many different potential applications in the field of cultural tourism (see Guttentag 2010).

VR refers to 'the use of a computer-generated 3D environment—called a 'virtual environment' (VE) - that one can navigate and possibly interact with, resulting in real-time simulation of one or more of the user's five senses' (Guttentag 2010, 638). AR refers to the 'projection of computer-generated images onto a real world view' (ibid).

Studies carried out at the intersections between ICT and cultural tourism, in contrast with studies in cultural heritage, mainly focus on the end-user, aiming at 
increased visitor engagement and personalisation or at the creation of immersive tourism experiences for the better promotion of cultural destinations (Bec et al. 2019; see also Jung et al. 2016; Kounavis et al. 2012). Moreover, a large corpus of studies focuses on the use of these technologies 'as an effective instrument for heritage management and preservation by generating substitute experiences' so as to minimise the tourists' effect on the actual sites/objects (Bec et al. 2019, 118). In this context, it is acknowledged that such applications can contribute to heritage preservation by minimizing the use of the original and offering an alternative in the form of visualisations and 3D reconstructions (Guttentag 2010).

In the context of the aforementioned studies, the notions of fidelity, immersion and presence are extremely important in determining the quality of experience provided by VR/AR technologies. Fidelity relates to the level of realism of the virtual environment (VE) and can be distinguished in visual, auditory or haptic depending on how realistic the environment looks, sounds or feels (Gilbert 2016). Immersion refers to 'the extent to which a user is isolated from the real world' (Guttentag 2010, 638). The various hardware equipment used for the VE are also related to the sense of immersion and can have an effect on the 'measure of psychological fidelity' (Gilbert 2016, 323). The concept of immersion is directly associated to the concept of 'presence', since it constitutes one of the factors influencing the user's sense of presence. Presence refers to the 'sense of being in a VE rather than the place in which the participant's body is actually located' (Sanchez-Vives and Slater, quoted in Guttentag 2010, 638), which tends to increase if the VE provides high quality data (ibid).

However, despite these notions and their role in the overall provided experience, the field lacks a discussion or a sound theoretical approach on the concept of authenticity in relation to VR/AR in cultural tourism. As illustrated by Yung and Khoo-Lattimore (2017), most studies at the intersection of ICT and cultural tourism focus on 'applied research and prototype development, with little consideration for underpinning theories, concepts, or frameworks' $(2017,16)$. Thus, more theorybased research is needed (Huang et al. 2016) and authenticity can constitute a part of this endeavour.

One such attempt was made by Gilbert, who acknowledged that 'what's missing from this dichotomy of immersion and presence is a computational theory about the extent to which the VE reflects the expected regularities of the world that it is attempting to represent-its authenticity' $(2016,322)$. According to Gilbert, 'immersion is the system-based factor that influences presence, and authenticity is the human-based factor that influences presence' (ibid, 323). However, this is one of the very rare references to authenticity in the context of ICT studies.

However, a growing academic discussion on authenticity has been developed in the field of 'archaeological computer graphics' or 'virtual heritage' (Pujol and Champion 2012), which lies at the intersections between ICT and archaeology. As Beale notes $(2018,83)$, 'considerations of authenticity have been instrumental in negotiating the value and meaning of computer-generated images in archaeology', with many discussions focusing on the authenticity of representation in reconstructions of the past. In this discussion many scholars stress the importance of accuracy 
in such representations, based on empirical data with the aim of transmitting archaeological knowledge to the public. In this context, authenticity is connected to archaeological and historic accuracy. As noted by Frischer et al. $(2000,8)$, 'accuracy and authenticity are two sides of the same coin. Accuracy pertains to the data and metadata; authenticity to the user's experience of the data and metadata'.

Nevertheless, once again authenticity proved a slippery notion, since as early as the 70s Walter Benjamin argued that a technological representation raises issues of authenticity since it redefines or alters the 'aura' of the original (see Benjamin 1968; Rickly-Boyd 2011). One can argue that no digital reconstruction, however high the quality of computer graphics is, or accurate the archaeological and historic knowledge is, can replace an original object. Newest discussions emphasize that in the case of archaeological computer graphics it is important to move away from the close alignment of authenticity with accuracy and acknowledge authenticity 'as a dynamic concept which is to be re-negotiated as required', since no matter how accurate a representation may be, 'its authenticity is always contingent on the perception of the viewer' (Beale 2018, 92).

In conclusion, ICT discussions of authenticity focus on the constructed experience from the point of view of immersion and accuracy of information. It is assumed that a higher level of immersion and the most accurate representation will offer a more authentic experience. The emphasis is on the construction of the experience and the user's experience.

\section{Applications and Implications for Cultural Tourism}

The many differences and discrepancies on the conceptualisation of authenticity between the three fields, also summarised in Table 1, are more than evident in the preceding analysis. The diverse conceptualizations are the result of the different priorities of each discipline. However, all three disciplines have a point of convergence. They all recognise that authenticity is a dynamic concept which cannot be rigidly defined and which evolves based on the needs of the involved stakeholders.

Table 1 Authenticity at the intersections of tourism studies, cultural heritage studies and ICT

\begin{tabular}{l|l|l}
\hline & Focus with regard to authenticity & Approaches towards authenticity \\
\hline $\begin{array}{l}\text { Tourism } \\
\text { Studies }\end{array}$ & The tourist and his/her perceptions & $\begin{array}{l}\text { Objectivist } \\
\text { Constructivist } \\
\text { Postmodernist }\end{array}$ \\
\hline $\begin{array}{l}\text { Cultural } \\
\text { Seritage }\end{array}$ & The object itself & $\begin{array}{l}\text { Evolution from an emphasis on } \\
\text { materials to a more relational and } \\
\text { socially constructed notion }\end{array}$ \\
\hline ICT & $\begin{array}{l}\text { Quality and accuracy of the representation } \\
\text { as part of a constructed experience. Terms } \\
\text { emphasised: fidelity, immersion and } \\
\text { presence }\end{array}$ & $\begin{array}{l}\text { A higher level of immersion and the } \\
\text { most accurate representation will } \\
\text { offer a more authentic experience }\end{array}$ \\
\hline
\end{tabular}


They also all recognise that as a concept, authenticity may encapsulate a range of perspectives which can exist simultaneously. Nevertheless, despite this conceptual fluidity, authenticity may be hard to decipher especially in light of the developments in new and emerging technologies and their effect on cultural tourism. As discussed in this section, the different perspectives developed may create problems in the application of VR/AR technologies in cultural tourism.

Authenticity conceptualisations in tourism studies don't come without implications. For example, the notion of 'objective authenticity' judged by criteria set by experts, resembles the AHD frame of thought, raising issues of power and authentication since it does not specify who has the power to set these criteria and determine authenticity (see Belhassen et al. 2008). This partly explains why many scholars adopted alternative perceptions of authenticity, advocating the abandonment of the objectivist approach (see for example Wang 1999).

However, new notions of post-modernism also pose implications by totally abandoning any conceptual value of objectivism. For example, by adopting the post-modern approach, Costa and Melotti suggest a 'hyper-authenticity' and a 'new relationship with the past' $(2012,55)$ stating that the tourist seeks an authenticity of 'experience and sensation'. In this perspective they suggest that the aim of VR/AR in heritage should be to create 'leisure and emotions' rather than an accurate reconstruction of the past. However, this imposes that the content becomes secondary since the most important aspect is leisure and emotion. Consequently, this devalues the educational aspect of cultural tourism and poses the threat to entirely lose the content just to 'create atmospheres and generate sensations' (Costa and Melotti 2012, 55). Finally, the tourist might be mainly interested in leisure and not too concerned with the accuracy of information he/she is exposed to, but nevertheless assumes that the information he/she receives is provided by experts and it is truthful and correct. This expectation is especially true for official institutions such as state museums and heritage sites (refer to Cameron 2005).

Moreover, it reduces the cultural tourism experience into something very narrow. In essence, it translates cultural tourism with a 'transaction-consumption' marketing perspective and reduces the cultural tourist into a 'customer-visitor' (Smith et al. 2012). As Belhassen et al. note, we cannot totally abandon objectivism, since this will mean that 'the idea of place, a central component of tourism,' will be lost (2008, 672). As they explain, 'when the objectivist approach to authenticity gets dismissed as ontologically untenable, the importance of the toured object and its "real", intersubjectively understood characteristics and meanings get tossed out along with it' (ibid, 671).

On the other hand, authenticity conceptualisations in heritage studies also come with a set of implications requiring further discussion. The institutionalised views of authenticity and the views stemming from the AHD result in two implications, which also affect cultural tourism and digital applications. First, most conceptualisations of authenticity emphasise the authenticity of the physical material. However, this proves problematic in the age of the digital transformation of heritage and cultural tourism, since it assumes a gap between the virtual and the material worlds, or a dichotomy between the original (and thus authentic) and the inauthentic replica 
(Witcomb 2010). In this frame of thought, once an object is reproduced (for example with the use of VR), it loses its aura and becomes a commoditised material or a merchandise. Therefore, 'authenticity cannot be reproduced, and disappears when everything is reproduced' (Di Franco et al. 2018, 2). However, is this actually the case? What if a digitally reproduced object can offer accurate information on the past, facilitate interpretations of the past for non-experts, create emotions and offer an 'authentic' experience to tourists?

Secondly, this AHD creates problems of authority which also affect the issue of authenticity. In the context of AHD, archaeologists and heritage managers claim expert authority over heritage and act as guardians of the 'physical' authenticity of heritage (Smith 2006). In this context, tourists are regarded as the 'destroyers' of fragile objects and sites (Ashworth 2009), who are not allowed to touch and may cause problems with their 'destroying behavior' (Smith 2012; see also Timothy and Boyd 2003). However, this proves problematic if translated in the age of the prevalence of digital technologies in cultural tourism, since as DiFranco et al. note, 'while audiences, communities and the public usually engage with this institutionalized past, new media, 3D technologies and the internet can, potentially, challenge the AHD' $(2018,2)$. Technologies such as VR and AR have greatly expanded the number of people that can come close to an object, which challenges not only the notion of authenticity but also the top-down approaches adopted by the AHD. Through technology the general audience can now freely navigate a VE, select what to see or for how long to interact with each given option. Although the content is still created by the experts, new technologies have helped non-experts voice their opinions and partially shape what is important through a slightly more critical engagement than before.

Moreover, another implication arising from the aforementioned views on authenticity is the tension between the 'necessity' of tourism and the destruction of authenticity. As Smith notes $(2012,210)$, although 'tourism brings in the economic resources to sustain and maintain heritage sites [...] tourists, by their very presence, are perceived to obliterate the cultural authenticity and ambience of heritage sites'. This perspective is linked to the fear of commodification, which is also used by heritage managers as an argument against the use of VR/AR technologies, which according to their concerns may commodify or devalue the significance and authenticity of heritage (see Smith et al. 2012). However, this creates new implications since as Silverman stresses, 'a fundamental aspect of authenticity in heritage is its problematical relationship to the global tourism economy in which it is embedded' $(2015,79)$.

As a result, the use of VR/AR is currently still limited in the heritage sector, partly due to a 'conservatism' on implementing such technologies, ${ }^{5}$ due to a fear that they will challenge the authenticity of a site and 'obstruct authentic experiences'

\footnotetext{
${ }^{5}$ The limited number of examples using VR/AR in museums and heritage sites can also be explained by the high cost of such applications and the constant need for maintenance, which is prohibitive especially for low-funded or small-scale museums.
} 
(Dueholm and Smed 2014, 286; see also Costa and Melotti 2012). This also relates to a fear of 'Disneyfication' or that VR/AR may turn heritage sites into theme parks (Timothy and Boyd 2003) by taking the entertainment aspect 'too far' and thus overpowering the educational message (Dueholm and Smed 2014).

Quite interestingly, some approaches seen in both tourism studies and heritage studies perceive an incompatibility between enjoyment/pleasure and education, falsely assuming that they cannot co-exist or be fulfilled at the same time (although many studies indicated the opposite, see for example Sylaiou et al. 2009).

Finally, the absence of discussions or theoretical underpinnings on authenticity in the ICT field (with the exception of 'archaeological computer graphics') may lead to a disregard of this notion in the developed applications. However, the field may largely contribute to new discussions on authenticity by stressing notions such as 'presence' and 'immersivity' in the discussions for the use of VR/AR in cultural tourism.

As evident from the above analysis, the three sectors examined have different and sometimes conflicting perspectives on what authenticity entails, which may create conflicts between involved stakeholders when attempts are made to incorporate VR/AR in cultural tourism. For example, in tourism studies many authors stress the importance of 'activity-related' authenticity, overlooking the authenticity of the 'toured objects', labelling this objectivist approach as conservatist. On the other hand, 'inauthenticity in objects, which existential authenticity to some extent ignores, is a serious problem' for heritage managers (Dueholm and Smed 2014, 292). This is further enhanced by the lack of critical and theory-based research on VR/AR in tourism studies and by the lack of established policies and guidelines ${ }^{6}$ to facilitate interdisciplinary endeavors and set the ground for further discussions.

\section{Conclusion}

As evident by the preceding analysis, the concept of authenticity is not only very important in determining the uses of VR/AR in cultural tourism but also extremely fluid and dynamic, incorporating facets of three different disciplines. As already discussed, the different and sometimes conflicting discourses appearing in the aforementioned disciplines are far more complex than they appear, creating much more implications than originally thought. Consequently, we argue that several things are needed so as to establish the authenticity of the experience offered by VR/AR applications in cultural tourism.

\footnotetext{
${ }^{6}$ The only set of guidelines established so far is the London Charter which focuses on computerbased visualizations of cultural heritage. However, the charter mainly focuses on documentation, data transparency and visualization quality. Refer to http://www.londoncharter.org/ (Accessed 3 June 2019).
} 
We should first recognise that it is unproductive to try to stress the points of difference between the aforementioned disciplines or choose between object-based or experience-based authenticity. We should rather acknowledge that a fair balance should be found so that the different needs and values of involved stakeholders are accommodated. Thus, these different perspectives on authenticity can co-exist and 'new technologies can be implemented to strengthen heritage sites as tourism attractions while still paying attention to authenticity' (Dueholm and Smed 2014, 297).

Moreover, we should also reconsider what cultural tourism entails. Is it merely a quest for the original (contrasted to the replica) or a quest for pure entertainment without any consideration of authenticity? And to add to this question, what can VR/AR offer to cultural tourism? A mere substitute of the original or a form of pure entertainment? We argue that the answer is 'neither'.

As Smith stresses, cultural heritage can be envisioned as a process which is 'critically active and self-conscious, through which people can negotiate identity and the values and meanings that underlie that, but through which they also challenge and attempt to redefine their position or 'place' in the world around them' $(2006,7)$. Thus, cultural tourism is associated with the creation of 'cultural moments of meaning' which signify both a 'physical and an emotional experience' (Smith 2012). Therefore, cultural tourism is not just about consumption but is also about embodiment and experience (ibid). Taking this as a starting point we can argue that authenticity in cultural tourism experiences should address both the physical dimension and the emotional/experiential one.

Third, a formalisation is also needed, through specific guidelines defining the boundaries, bringing together the needs and values of heritage managers and the cultural tourism industry or the local stakeholders. As shown in the analysis, the discussion on authenticity is extremely interdisciplinary with many different approaches and perspectives. Thus, such a 'formalisation', which would be based on new interdisciplinary definitions of authenticity, would facilitate and safeguard the needs and values of all involved disciplines/stakeholders and set the boundaries of misconduct. This would also offer more conceptual clarity not only on the notion of authenticity per se but also on other concepts associated with it such as experience, 'immersivity' and presence. These concepts also affect authenticity, which, as shown in this paper, is not acknowledged in all analysed disciplines. By integrating such concepts to a re-conceptualisation or formalisation of authenticity, we can facilitate interdisciplinary definitions and explorations of their effect on cultural tourism.

Finally, in order to achieve the successful integration of new technologies in cultural tourism it is imperative to involve all related disciplines so as constructive collaborations are achieved. Each of the aforementioned disciplines has something to offer in this discussion but, as was evident in the analysis, no one discipline can work alone or claim absolute expertise without the valuable contributions or technological skills of other disciplines. Thus, creative and interdisciplinary collaborations are needed so as to achieve the creation of truly transformational experiences for cultural tourists. 
Acknowledgements This research is part of the project that has received funding from the European Union's Horizon 2020 research and innovation programme under grant agreement No 739578 (RISE - Call: H2020-WIDESPREAD-01-2016-2017-TeamingPhase2) and the Government of the Republic of Cyprus through the Directorate General for European Programmes, Coordination and Development.

\section{References}

Aplin, G. (2002). Heritage: Identification, conservation, and management. South Melbourne: Oxford University Press.

Ashworth, G. J. (2009). Do tourists destroy the heritage they have come to experience? Tourism Recreation Research, 34(1), 79-83.

Beale, G. (2018). Volatile images: Authenticity and representation and multi-vocality in digital archaeology. In Authenticity and cultural heritage in the age of $3 D$ digital reproductions (pp. 83-93). Cambridge: McDonald Institute for Archaeological Research.

Bec, A., Moyle, B., Timms, K., Schaffer, V., Skavronskaya, L., \& Little, C. (2019). Management of immersive heritage tourism experiences: A conceptual model. Tourism Management, 72, 117-120.

Belhassen, Y., Caton, K., \& Stewart, W. P. (2008). The search for authenticity in the pilgrim experience. Annals of Tourism Research, 35, 668-689.

Benjamin, W. (1968). The work of art in the age of mechanical reproduction. In W. Benjamin (Ed.), Illuminations (trans. Harry Zohn) (pp. 217-251). New York: Schocken Books.

Cameron, F. (2005). Contentiousness and shifting knowledge paradigms: The roles of history and science museums in contemporary societies. Museum Management and Curatorship, 20(3), 213-233.

Chhabra, D., Healy, R., \& Sills, E. (2003). Staged authenticity and heritage tourism. Annals of Tourism Research, 30, 702-719.

Cohen, E. (1995). Contemporary tourism-Trends and challenges: Sustainable authenticity or contrived post-modernity? In R. Butler \& D. Pearce (Eds.), Change in tourism: People, places, processes (pp. 12-29). London: Routledge.

Cohen, E., \& Cohen, S. A. (2012). Authentication: Hot and cool. Annals of Tourism Research, 39, $1295-1314$.

Costa, N., \& Melotti, M. (2012). Digital media in archaeological areas, virtual reality, authenticity and hyper-tourist gaze. Sociology Mind, 2, 53-60.

Di Franco, P., Galeazzi, F., \& Vassallo, V. (2018). Why authenticity still matters today. Authenticity and cultural heritage in the age of $3 D$ digital reproductions (pp. 1-9). Cambridge: McDonald Institute for Archaeological Research.

Dueholm, J., \& Smed, K. (2014). Heritage authenticities - a case study of authenticity perceptions at a Danish heritage site. Journal of Heritage Tourism, 9(4), 285-298.

Frischer B., Niccolucci F., Ryan N \& Barceló, J. (2000). From CVR to CVRO: The past, present, and future of cultural virtual reality. In Virtual archaeology between scientific research and territorial marketing: Proceedings of the VAST EuroConference, Arezzo, Italy, 1-12.

Gilbert, S. B. (2016). Perceived realism of virtual environments depends on authenticity. Presence: Teleoperators and Virtual Environments, 24, 322-324.

Guttentag, D. A. (2010). Virtual reality: Applications and implications for tourism. Tourism Management, 31, 637-651.

Huang, Y. C., Backman, K. F., Backman, S. J., \& Chang, L. L. (2016). Exploring the implications of virtual reality technology in tourism marketing: An integrated research framework. International Journal of Tourism Research, 18(2), 116-128. 
Jung, T. H., tom Dieck, M. C., Lee, H., \& Chung, N. (2016). Effects of virtual reality and augmented reality on visitor experiences in museum. In A. Inversini \& R. Schegg (Eds.), Information and communication technologies in tourism (pp. 621-635). Cham, Switzerland: Springer.

Kounavis, C. D., Kasimati, A. E., \& Zamani, E. D. (2012). Enhancing the tourism experience through mobile augmented reality: Challenges and prospects. International Journal of Engineering Business Management, 4(1), 1-6.

Lowenthal, D. (1990). The past is a foreign country. Cambridge: Cambridge University Press.

Lowenthal, D. (1999). Authenticity: Rock of faith or quicksand quagmire? The Getty Conservation Institute Newsletter, 14(3), 5-8.

MacCannell, D. (1973). Staged authenticity: Arrangements of social space in tourist settings. American Journal of Sociology, 79(3), 589-603.

Pujol, L., \& Champion, E. (2012). Evaluating presence in cultural heritage projects. International Journal of Heritage Studies, 18(1), 83-102.

Rickly-Boyd, J. (2011). Authenticity \& aura: A Benjaminian approach to tourism. Annals of Tourism Research, 39(1), 269-289.

Ruskin, J. (1849). The seven lamps of architecture. Retrieved from http://www.victorianweb.org/ authors/ruskin/7lamps/6.html\#30

Silverman, H. (2015). Heritage and authenticity. In E. Waterton \& E. Watson (Eds.), The Palgrave handbook of contemporary heritage research (pp. 69-88). New York: Palgrave Macmillan.

Smith, L. J. (2006). Uses of heritage. London: Routledge.

Smith, L. J. (2012). The cultural 'work' of tourism. In L. Smith, E. Waterton, \& S. Watson (Eds.), The cultural moment in tourism (pp. 210-234). Oxon: Routledge.

Smith, L., Waterton, E., \& Watson, S. (Eds.). (2012). The cultural moment in tourism. London and New York: Routledge.

Sylaiou, S., Liarokapis, F., Kotsakis, K., \& Patias, P. (2009). Virtual museums, a survey and some issues for consideration. Journal of Cultural Heritage, 10, 520-528.

Timothy, D., \& Boyd, S. W. (2003). Heritage tourism. Harlow: Prentice Hall.

Wang, N. (1999). Rethinking authenticity in tourism experience. Annals of Tourism Research, 26 (2), 349-370.

Witcomb, A. (2010). The materiality of virtual technologies: A new approach to thinking about the impact of multimedia in museums. In S. Kenderdine \& F. Cameron (Eds.), Theorizing digital cultural heritage: A critical discourse (pp. 35-48). Cambridge (MA): MIT Press.

Yung, R., \& Khoo-Lattimore, C. (2017). New realities: A systematic literature review on virtual reality and augmented reality in tourism research. Current Issues in Tourism, 2017, 1-25. 